\title{
AMOR Y METAFÍSICA. UNA REFLEXIÓN ACERCA \\ DE LA FILOSOFÍA PRIMERA
}

\section{LOVE AND METAPHYSICS. A REFLECTION ON \\ THE FIRST PHILOSOPHY}

\author{
IGNACIO VERDÚ BERGANZA \\ Universidad Pontificia Comillas
}

Recibido: 16/10/2018

Aceptado: 23/01/2019

\section{RESUMEN}

Siguiendo como guía a San Buenaventura, pretendo mostrar en qué medida el aristotelismo pierde profundidad metafísica respecto del platonismo y, sobre todo, qué añade el cristianismo y su concepción del amor a la filosofía entendida como metafísica.

Palabras clave: Aristóteles, Platón, Plotino, San Agustín, San Buenaventura, amor, creación, libertad, necesidad, sabiduría.

\section{ABSTRACT}

Following, as a guide, St. Bonaventure intended to show the extent to wich aristotelism loses metaphysical Depth over platonism and, above all, what adds christianity and its idea of love to philosophy understood as metaphysics.

Keywords: Aristotle, Plato, Plotino, St. Augustin, St. Bonadventure, love, creation, freedom, need, wisdom. 
"La puerta de la sabiduría es la concupiscencia y vehemente deseo de ella, de ahí que leamos en el salmo: abre bien tu boca, que yo te saciaré plenamente. Este es el camino por donde viene a mí la sabiduría, por donde entro yo en la sabiduría y la sabiduría entra en mí"1.

"Quien no es pues, como Daniel, hombre de deseos, no está preparado de ningún modo para las divinas contemplaciones, que conducen al desbordamiento del alma", 2 .

"Nada sacia al alma si no sobrepasa su capacidad"3.

He acudido a la autoridad del doctor seráfico para comenzar este escrito, y este hecho, ya de por sí, es sumamente revelador. Pretendo compartir una reflexión acerca de la filosofía primera, es decir, acerca de la filosofía en su sentido más profundo y radical; no en un sentido derivado. Y lo hago convencido de que la filosofía primera es metafísica. Sin embargo, como bien puede colegirse de la compañía que he buscado, no es Aristóteles mi guía en este terreno, y no lo es en la medida en que entiendo que desdeña lo que considero capital del platonismo y no vislumbra, no puede, la que será la gran novedad que introduce Agustín en el ámbito de la filosofía.

Para San Buenaventura la grandeza del platonismo, de la propuesta de los que él llama filósofos iluminados, nobles, verdaderos ${ }^{4}$, desatendida por Aristóteles, reside en su convicción de que lo que hace del hombre el ser que es es el hecho de saber, lo quiera o no, de la belleza, de la verdad, en definitiva, del Bien, Luz, Logos; aun habitando en las sombras, entre la fealdad del desorden, sumido en ignorancia y maldad.

Reside, en verdad, en concebir un Logos, divino, como fundamento y vida de este mundo y de cada uno de nosotros; Logos que hemos olvidado, aunque nunca de modo pleno; Luz, Vida de nuestra vida, Luz de toda luz. Y en afirmar, así mismo, que no es posible la felicidad para el hombre, la plenitud, si no se compromete con el Logos, y con nada más; si no vive en constante esfuerzo de purificación, para que se manifieste lo oculto, pero siempre presente: reminiscencia.

1 San Buenaventura, Colaciones sobre el Hexaémeron, Col. II, 2, en Obras de San Buenaventura, tomo III, (Madrid: B.A.C., 1947), 204 y 205.

2 San Buenaventura, Itinerario de la mente hacia Dios, Prol. 3, en Experiencia y teología del misterio, (Madrid: B.A.C., 2000), 6.

3 San Buenaventura, Cuestiones disputadas de la ciencia de Cristo, Cuestión VI, Conclusión (Murcia: Editorial Espigas, 1999), 218-219.

4 San Buenaventura, Colaciones sobre el Hexaemeron, col. VI, 1, 2, 27 y col. VII, 4. 
Agustín, en un texto extraordinario de sus Confesiones, obra clave también en este contexto, había señalado, con asombro y entusiasmo, que había leído en "ciertos libros de los platónicos, traducidos del griego al latín-sin duda se trataba de las Enéadas de Plotino traducidas por Mario Victorino-no ciertamente con estas palabras, pero si sustancialmente lo mismo, apoyado en muchas y diversas razones, -tal y como podía leerse en el texto revelado de San Juan en el Nuevo Testamento-que en el principio era el Verbo-Logos, y el Verbo-Logos estaba en Dios. Y Dios era el Verbo-Logos. Este estaba desde el principio en Dios. Todas las cosas fueron hechas por Él, y sin Él no se ha hecho nada"5.

Esta era, sin lugar a dudas, una afirmación extraordinaria y de un calado profundísimo; una afirmación de un platónico acorde con la revelación, que un cristiano como Agustín no podía leer sino con admiración y asombro. Pero, más adelante, en el texto antes citado de las Confesiones, afirmaba que también había leído en Plotino "que el alma del hombre, aunque da testimonio de la luz, no es la luz, sino el Verbo-Logos, Dios"; ; Y añadía, siguiendo el texto de San Juan, algo de gran importancia: "que es -el Verbo, el Logos-la luz verdadera que ilumina a todo hombre que viene a este mundo"7 .

"También -continuaba Agustín- leí allí que el Verbo-Logos, Dios, no nació de carne ni de sangre, ni por voluntad de varón, ni por voluntad de carne, sino de Dios. [...] Igualmente hallé en aquellos libros, dicho de diversas y múltiples maneras, que el Hijo tiene la forma del Padre y que no fue rapiña juzgarse igual a Dios por tener la misma naturaleza que él", ${ }^{, 8}$. Y, por último, afirmaba: "Allí se dice también que antes de todos los tiempos, y por encima de todos los tiempos, permanece inconmutablemente tu Hijo unigénito, coeterno contigo, y que de su plenitud reciben las almas para ser felices y que por la participación de la sabiduría permanente en sí son renovadas para ser sabias"9.

Estas afirmaciones constituían, para Agustín y sus seguidores, el más elevado y profundo logro de los más destacados filósofos griegos, los platónicos. Hasta aquí habían llegado en su esfuerzo filosófico. Cierto es que, como confiesa, no había leído allí que "vino a casa propia y los suyos no lo recibieron, y que a cuantos le recibieron les dio potestad de hacerse hijos de Dios creyendo en su nombre" 10 , ni había encontrado en esos magníficos textos que "se

5 San Agustín de Hipona, Confesiones, VII, 9, 14, en Obras de San Agustín, Tomo II, (Madrid: B.A.C., 1998), 283.

6 San Agustín, Confesiones, VII, 9, 14, 283.

7 San Agustín, Confesiones, VII, 9, 14, 283.

8 San Agustín, Confesiones, VII, 9, 14, 283.

9 San Agustín, Confesiones, VII, 9, 14, 284.

10 San Agustín, Confesiones, VII, 9, 14, 283. 
anonadó a sí mismo, tomando la forma de siervo, hecho semejante a los hombres y reconocido por tal por su modo de ser; y que se humilló, haciéndose obediente hasta la muerte, y muerte en la cruz" ${ }^{11}$. Y es que el platonismo, culminación del filosofar griego para Agustín, no es cristianismo, no bebe de la revelación del Logos encarnado.

Según el platonismo, tal y como lo entendía Agustín, sabemos de la Verdad, y por ello buscamos, preguntamos, indagamos; sabemos de la Belleza, y por ello nos asombramos, nos maravillamos; sabemos del Bien, y por ello sufrimos con el mal y anhelamos, deseamos; aunque devenimos, nacemos y morimos, día a día, sabemos de la eternidad, y por ello nos angustiamos con el paso del tiempo, nos espantamos ante la muerte y no nos entendemos. La clave está en el interior, en la intimidad más entrañable y cercana.

Para el aristotelismo, sin embargo, somos como una página en blanco esperando a ser afectada por lo externo a ella, a recibir impresiones que dejen su huella. No venimos al mundo sabiendo de lo que anhelamos, habiendo olvidado y habiendo de recordar. No hay un Logos que es Luz de toda luz, Verdad de toda verdad, Bien de todo bien; Causa ejemplar.

Así las cosas, para el aristotélico, en verdad la filosofía no es un compromiso vital, integro, existencial, con el Bien y, así, un ejercicio personal, definitivo y constante de purificación, de limpieza y desasimiento, encaminado a dejar que sea la luz del Bien, de la Verdad, la que, por fin, resplandezca en nuestra intimidad, sea nuestra vida; como si lo es para el platónico, enraizado en la herencia socrática, dispuesto a entregar su vida, a perderla, antes de romper su compromiso, antes de traicionar al Logos, antes de hundirse en el negro olvido sin retorno, en el Hades más oscuro y lejano.

El aristotelismo entiende la filosofía, en su sentido más estricto, como ciencia, no como vida; como saber teórico, visión; no práctico. Así las cosas, la filosofía $1^{\mathrm{a}}$ es la ciencia, el conocimiento, de las primeras causas y principios de todo lo real; de la necesidad que todo lo rige desde el inicio, de los encadenamientos irrompibles de causas y efectos, del ser, que no puede ser sino el que es, lo que es y como es. Y la ciencia es claridad, quietud, fin, que es comienzo; reposo, que es felicidad; eternidad, necesidad.

Es cierto que Aristóteles afirma que todo hombre desea; pero lo que desea es saber. Alcanzado el saber se apaga, suprime, el deseo. Y el saber no se anhela por otra cosa que por saber; no se anhela porque sea bueno, sino por ser la culminación de un proceso cerrado y prefijado desde el inicio, por ser lo que desde

11 San Agustín, Confesiones, VII, 9, 14, 283-4. 
un principio viene marcado en la naturaleza como fin, por ser el fin que desde siempre ha estado presente en el principio, el fin irrevocable; arche que todo lo mueve, desde siempre, con implacable necesidad.

Es el saber, el conocer, el ver, el verdadero inicio y el final de todo. El deseo y el asombro son momentos accidentales; aunque extrañamente necesarios, no esenciales, del ser de lo real.

El deseo, el querer, se agota en el saber; se agosta. El saber es vida y es quietud; la ausencia de distancia, la identidad perfecta: la luz del ser. Sólo desea el que no sabe, solo se asombra, se maravilla, el que no sabe; el que aún está a distancia, en la distancia: distanciado.

"Todos los hombres desean saber"12, había escrito Aristóteles al inicio de su estudio sobre la filosofía $1^{\mathrm{a}}$, y añadía más adelante: "el que se siente perplejo y maravillado reconoce que no sabe" ${ }^{\text {. }}$. Ahora bien, si bien el saber del que trata, el propio de los filósofos, es un saber que se busca por el mero saber, "pues, si filosofaron por huir de la ignorancia, es obvio que perseguian el saber por afán de conocimiento y no por utilidad alguna" ", afirma Aristóteles con decisión que: "la posesión de esta ciencia ha de cambiarnos, en cierto sentido, a la actitud contraria (de la que corresponde) al estado inicial de las investigaciones. $Y$ es que, como decíamos, todos comienzan maravillándose de que las cosas sucedan como suceden: así ocurre, por ejemplo, en relación con los autómatas de los teatros de marionetas [eso les pasa a los que no han visto la causa], o en relación con las revoluciones del sol, o con la inconmensurabilidad de la diagonal (a todos, en efecto, maravilla [a los que no han visto la causa] que algo no pueda medirse ni con la más pequeña de las medidas). Es preciso, sin embargo, que se imponga la actitud contraria y que es la mejor, según el refrán, como ocurre incluso en estos casos, una vez que se ha aprendido: nada, desde luego, maravillaría tanto a un geómetra como que la diagonal resultara conmensurable",15.

Este saber, divino, es el saber de la causa, que es el que la causa tiene de sí misma. La causa $1^{\mathrm{a}}$, que es motor primero, es la causa final, ser en acto, sustancia $1^{\mathrm{a}}$, pensamiento perfecto, contemplación, visión plena de sí misma.

El platónico, tal y como lo entenderá la tradición agustiniana, lejos de entender que la causa última, el principio $1^{\circ}$ de todo lo real, es el ser, en acto, que es pensamiento que se auto sustenta, afirma el Uno-Bien como causa $1^{\mathrm{a}}$ y última,

12 Aristóteles, Metafisica I, 1, 980ª 20, (Madrid: Gredos, 1994), 69.

13 Aristóteles, Metafisica I, 2, 982b 15-20, 76-7.

14 Aristóteles, Metafisica I, 2, 982b 20-22, 77.

15 Aristóteles, Metafisica I, 2, 983a 10-20, 78. 
de la que todo pende, sin la que nada es ni tiene sentido. Y el deseo, frente a Aristóteles, no es deseo del mero saber, sino del Bien.

La filosofía es anhelo, deseo, de sabiduría, pero la sabiduría no es el saber entendido como ciencia teórica, visión, sino el reconocimiento del Bien como aquello que merece nuestra adhesión, nuestra entrega; aquello que exige nuestra transformación, conversión, y la posibilita. Aquello por lo que merece la pena la vida y, por tanto, entregarla. Y es que, decía Platón: "así como el ojo no puede volverse hacia la luz y dejar las tinieblas si no gira todo el cuerpo, del mismo modo hay que volverse desde lo que tiene génesis con toda el alma, hasta que llegue a ser capaz de soportar la contemplación de lo que es, y lo más luminoso de lo que es, que es lo que llamamos el Bien" $"$.

Para el platonismo, tal y como lo entenderá su apasionado interprete Plotino, la culminación del deseo no es el saber estático, sino la entrega y el abandono, más allá de nuestro saber, al Bien que todo lo sustenta y funda, al bien que debe reinar.

"Hay que volver -decía Plotino en la primera de sus Enéadas-pues, a subir hasta el Bien, que es el objeto de los deseos de toda alma. Si alguno lo ha visto, sabe lo que digo; sabe cuán bello es. Es deseable, en efecto, por ser bueno, y el deseo apunta al Bien; mas, la consecución del Bien es para los que suben hacia lo alto, para los que se han convertido y se despojan de las vestiduras que nos hemos puesto al bajar, [...] hasta que, pasando de largo en la subida todo cuanto sea ajeno a Dios, vea uno por si solo a él solo incontaminado, simple y puro, de quien todas las cosas están suspendidas, a quien todas miran, por quien existen y viven y piensan, pues es causa de vida, de inteligencia y de ser" 17 . " $Y$ en esto consiste pensar -añadirá en la quinta Enéada- en un movimiento hacia el Bien por deseo del Bien"18.

El Bien, afirmaba Plotino en un texto extraordinario, "Transforma en bellos a sus enamorados y los hace dignos de ser amados" 19 . Porque, explicaba en la sexta Enéada "el alma misma, cuando concibe un amor intenso por aquél [el Uno-Bien], depone todas las formas que tiene, incluso cualquier forma de orden inteligible que haya en ella. Porque si uno trae entre manos alguna otra cosa y centra su actividad en ella, ya no puede ni ver a aquél ni adecuarse a él. No 
debe tener a mano ninguna otra cosa, a fin de que reciba sola al Solo"20 "Despójate de todo" 21 , este era el imperativo plotiniano.

Recibir solo al Solo es la culminación de la búsqueda, del deseo, del anhelo que moviliza al filósofo. Y solo es posible cuando uno se entrega plenamente y no guarda nada. Y una vez que el Bien se haga presente en el alma, proclamará Plotino con profundidad y desconcertante belleza: "cuando ella se haya desinteresado de las cosas presentes preparándose lo más hermosa posible y asemejándose al Bien, [...] una vez, pues, que el alma vea al Bien apareciendo de súbito dentro de ella [...], entonces sí que no cambiaría el Bien por nada del mundo, asi le ofrecieran el mundo entero, sabiendo como sabe que no hay nada mejor que el Bien, nada más bien que el Bien. [...] Y todas aquellas cosas en las que antes se deleitaba-mandos, poderes, riquezas, bellezas, ciencias-de todas esas cosas habla desdeñosamente. [...] Y se halla entonces en una disposición tal que aun el pensar, tan bien acogido el resto del tiempo, lo tiene por poco" $^{\text {,2 }}$. Y es que, llega a afirmar, la inteligencia se transforma en inteligencia enamorada, enajenada y "embriagada de néctar"; y todo esto para terminar clamando: ";Y más vale emborracharse con semejante borrachera que guardar la compostura!"23.

Detengámonos un poco más, insistamos en este punto crucial. El pensamiento medieval cristiano recogerá con entusiasmo este pensamiento, y lo llevará más allá. Ciertamente eran y son extraordinarias, por precisas y profundas, las palabras de un platónico, Dionisio areopagita, reconocido y admirado por el pensador franciscano que he adoptado como guía en estas reflexiones. En su tratado dedicado a los nombres divinos, texto leído con veneración durante siglos, en línea con lo afirmado por San Gregorio de Nisa en su impactante Vida de Moisés ${ }^{24}$, afirmaba: "Cualquier palabra o concepto resultan inadecuados para expresar lo desconocido de la supraesencia, que está muy por encima de todo ser. Necesitamos para esto un conocimiento supraesencial",25. Y, es así, porque "Aquella infinita supraesencia trasciende toda esencia [...] Está más allá de toda inteligencia. Ningún razonamiento puede alcanzar aquel Uno inescrutable. No hay palabras con que poder expresar aquel Bien inefable [...] Él mismo está fuera de las categorías del Ser" ${ }^{26}$. No es pues razonando como

20 Plotino, Enéadas, VI, 7, 34, 473.

21 Plotino, Enéadas, V, 3, 17, 85.

22 Plotino, Enéadas, VI, 7, 34, 473-4.

23 Plotino, Enéadas, VI, 7, 35, 476.

24 San Gregorio de Nisa, Vida de Moisés, (Salamanca: Sígueme, 1993).

25 Pseudo Dionisio Areopagita, Los nombres de Dios, c. I, 585 B, en Obras completas del Pseudo Dionisio Areopagita, (Madrid: B.A.C., 1990), 269.

26 Pseudo Dionisio, Los nombres de Dios, c. I, 588 B, 270. 
alcanzamos lo que buscamos, como logramos dar alcance a lo que anhelamos, deseamos... Es entregándonos a aquello que está más allá del ámbito de nuestro poder, poniéndonos en sus manos, como logramos la ciencia que sobrepuja toda ciencia y la trasciende: "Enamorarse de Dios lleva al éxtasis, pues quienes así aman están en el amado más que en sí mismos" ${ }^{27}$, sentencia Dionisio.

Muchos siglos después, en unos textos luminosos, precisos y preciosos, un sobrecogedor místico mostrará la fuerza y vigencia de estas ideas:

"Y si lo queréis oír

Consiste esta suma ciencia

En un súbito sentir

De la divinal esencia;

Es obra de tu clemencia

hacer quedar no entendiendo

toda ciencia trascendiendo.

$[\ldots]$

Olvido de lo criado

memoria del criador

Atención al interior

Y estarse amando al amado"28.

La potencia de las propuestas platónicas se mostraba innegable. Pero la propuesta aristotélica, su confianza en el poder de la razón, del razonar, así mismo, es de una fuerza arrolladora. Aristóteles no solo pretendía demostrar que su sistema era el verdadero de hecho; se ocupó de confirmar mediante argumentos no objetables, como un adelantado discípulo de Parménides, su carácter necesariamente verdadero; que las cosas responden a un orden inquebrantable y no pueden ser sino como son, tal y como ocurre, lógicamente, con el conocimiento de ellas $^{29}$.

27 Pseudo Dionisio, Los nombres de Dios, c. I, 13, 712 A, 307.

28 San Juan de la Cruz (1989), Coplas del mismo hechas sobre un éxtasis de harta contemplación, 8, y Letrillas (Suma de la perfección), 2, en Obras completas, (Madrid: B.A.C., 1989), 37 y 41.

29 Ana María Carmen Minecan, "1210-1277: la condena de la física aristotélica. Los albores del método hipotético deductivo", en Francisco León Florido (Coord), Las condenas de Aristóteles en la Edad Media, (Valencia: Kyrios, 2012), 105-140. 
Aristóteles vinculaba esencialmente ciencia y necesidad, ciencia y eternidad, ciencia e inmutabilidad. Y la contingencia no podía ser, por tanto, sino ignorancia. Dios, pensamiento que se piensa a sí mismo, ciencia en acto, es necesidad, Ser en plenitud, eternidad, y nada fuera de él es, ni es pensable. Se podía leer en su Ética a Nicómaco: "Todos pensamos que aquello de que tenemos ciencia no puede ser de otra manera; de lo que puede ser de otra manera, cuando tiene lugar fuera del alcance de nuestra observación, no sabemos si es o no es. Por consiguiente, lo que es objeto de ciencia es necesario. Luego es eterno, ya que todo lo que es absolutamente necesario es eterno, y lo eterno, ingénito e imperecedero"30.

La confianza aristotélica en el poder de la razón era de un atractivo casi irresistible. Parecía establecer que las relaciones de causa y efecto no son sino relaciones de consecuencia lógica; necesarias, por tanto. Y esto, como bien comprendieron algunos de sus lectores, implicaría que lo que es es porque no puede no ser y no puede ser sino como es. Quien llegue, pues, a conocer plenamente todas las relaciones entre las causas y sus efectos y todas las series causales, es decir, el orden necesario que rige el cosmos, el ser de todo lo que es, actualizará plenamente las potencias de su intelecto y conocerá el Logos de la naturaleza, de todo lo real, como Dios mismo.

La fuerza demostrativa se muestra como el camino a la plenitud, a la Luz, a la felicidad; proponiéndose como ciencia $1^{\mathrm{a}}$, ciencia por excelencia, fundamento de cualquier otra ciencia, la ciencia del Ser; así se entenderá la metafísica.

Para un pensador profundo como San Buenaventura un camino y otro, una propuesta filosófica y otra, platonismo y aristotelismo, eran irreconciliables. Y lo eran porque conducían a metas diferentes por caminos distintos. En línea con su gran referente, San Agustín, el maestro parisino está convencido de que Aristóteles ha rebajado la metafísica al nivel de la física; ha degradado la metafísica, y con ello la filosofía. Y es por esto por lo que su obra, como la de algunos de sus comentadores, puede llegar a ser un grave peligro para la filosofía misma.

Había dicho San Agustín en su tratado sobre la Trinidad que "Los que disputan acerca de la sabiduría la definen diciendo: "Sabiduría es la ciencia de las cosas divinas y humanas". [...] Pero al tenor de la distinción del Apóstol, donde dice que a uno le ha sido dada palabra de sabiduría y a otro, palabra de ciencia, es menester dividir dicha definición, llamando, en sentido propio, sabiduría a la ciencia de las cosas divinas, y dando el nombre de ciencia al

30 Aristóteles, Ética a Nicómaco, VI, 3, 1139b, (Madrid: Centro de estudios constitucionales, 1989), 91. 
conocimiento de las humanas" 31 . Y, tomando estas palabras como referencia, añadirá San Buenaventura: "Parece habérsele concedido a Platón, a diferencia de los otros filósofos el lenguaje de la sabiduría, y a Aristóteles el de la ciencia. Aquel miraba señaladamente hacia lo alto; este, en cambio, hacia lo bajo principalmente $^{\text {,32. }}$.

Acontece, sin embargo, algo de importancia capital, que merece reflexión profunda: siendo esto así, aun habiéndosele concedido a Platón el lenguaje de la sabiduría, aun mirando hacia lo alto, hablando de lo divino, el platonismo no puede abandonar definitivamente lo que sería las claves de la razón filosófica griega; su lógica propia.

El platonismo, como culmen del pensamiento griego, siendo extraordinariamente profundo, no puede llegar a donde ha de llegar un pensamiento iluminado por el Logos encarnado, por el cristo crucificado; un pensamiento enraizado en el escándalo y la locura, que es radical, entrañable, Sabiduría.

La locura del mensaje cristiano, para un platónico, estriba, entre otras cosas, en que no se afirma que Dios dirige de cerca un cuerpo, una carne, el ámbito de los finito, perentorio, efímero, caduco, del mismo modo que el piloto gobierna la nave; no es que se una a ello para conocerlo; es que se hace carne, tiempo, historia: hombre.

Pero la locura de la nueva filosofía no queda en esto, el cristianismo afirma con rotundidad la encarnación de Dios, y por tanto que la carne no es Dios, que no queda subsumida en lo divino; pero no porque sea lo opuesto a lo divino, no porque no sea bella, sino porque el tiempo, la historia, no es un momento del eterno devenir de lo divino: hay creación. Y junto a todo esto afirma, además y consecuentemente, que el hombre es creación, es decir, carne; que el alma del hombre es carne; que el hombre no es Dios, que aprender no es recordar lo que ya, desde siempre, conocimos, que alcanzar sabiduría y felicidad no es volver a ser lo que ya fuimos y, por tanto, siempre hemos sido y somos, eternamente.

El cristianismo afirma con absurda firmeza la alteridad absoluta de Dios respecto del hombre, respecto de la creación; y, por tanto, la inalienable trascendencia de Dios. Y afirma, además, un tiempo nuevo, pues nadie puede, limpiándose por completo, purificándose hasta el extremo, volver a ser lo que fue, pues antes de ser tiempo, devenir, apertura a lo aún no siendo, era nada. El presente no mira hacia el pasado sino siempre hacia el futuro; el presente no es el espacio

31 San Agustín de Hipona, La Trinidad, L. XIV, C. II, 3, en Obras completas V, (Madrid: B.A.C., 2006), 645-6.

32 San Buenaventura, Cristo, Maestro único de todos, 18, en Obras I, (Madrid: B.A.C., 2010), 5834. 
que habitamos, desde siempre, y del que hemos de expulsar todo aquello que nos impide mostrarnos tal y como en verdad somos; el presente es siendo, apertura, apertura a lo otro que yo: tiempo.

La creación y la encarnación hablan de un Dios que se entrega por lo otro que él, pues de otro modo no hay entrega; que no se guarda nada. De un Dios que no es un eterno saber de sí, vuelto sobre sí, autosatisfecho, sino amor.

Así, el presente, el tiempo que es mi vida, como apertura a lo otro que yo, es apertura a Dios; a un Dios que se me da, que me ama; que no me subsume en su inmensidad, sino que me constituye y recrea como otro que Él con su donación, elevándome a la sobrecogedora condición de amado, llamado, apelado, a amar: en devenir. Que me despierta, para siempre, haciendo de mi vida drama, historia, anhelo, deseo, búsqueda; dolor y regocijo.

Decía Kierkegaard en Migajas filosóficas que el pathos griego se concentra en la reminiscencia; que es saber. En el hecho de que, si es posible la sabiduría, lo es porque aquello por saberse ya es sabido. En último término, en que el presente no esté abierto al futuro, siendo así que el futuro es lo realmente inanticipable; en que no haya acontecimiento en el sentido más profundo del término. No sólo es que para saber algo sea necesario que eso por saber de algún modo ya sea, y solo puede ser si es sabido, es decir, si está definido, es que, y esta es la clave, quien desea saber solo puede desear y solo puede saber en la medida en que ya lo sabe todo. Solo ha de recordar; volver a ser lo que fue, regresar al comienzo. No hay otro modo de garantizar la Luz; la felicidad como plenitud y claridad.

Pero así, en verdad, no es formulable la alteridad radical, la irrupción de la novedad, la vivificante trascendencia. El tiempo, entendido como el ser del ser, se cierra sobre sí. Es así, tal vez, como el filósofo griego cree escapar al sinsentido y al miedo; renunciando a la vida.

Agustín, como clamaba todo platónico, sabe que, aunque queramos, no podemos fundirnos con el mundo, ser quienes somos y quedar reducidos a un trozo sin más del extraordinario cosmos, una cosa entre las cosas, pero esto es así no porque seamos divinos, no porque habitásemos otra realidad, olvidada, a la que hemos de regresar, sino porque somos interpelados, invitados, aunque no queramos, desde más allá del ámbito de nuestro poder, en lo más íntimo de nuestra intimidad, a confiar en la llamada de lo que nos excede, a esperar de lo que no podemos afianzar ni hemos asegurado, y a entregarnos, darnos: amar.

"iTarde te ame, hermosura tan antigua y tan nueva, tarde te ame! Y he aqui que tu estabas dentro de mí, y yo fuera, y por fuera te buscaba [...] Tú estabas 
conmigo, más yo no estaba contigo"33. "Porque tú estabas dentro de mí, más interior que lo más íntimo mío y más elevado que lo más sumo mío"34.

La necedad de San Agustín, confesada por él, consistió en pretender que podía contentarse con lo que podía someter a su poder, a su saber, a su rendimiento. Y es así porque, como suyo, siempre sería inmanente; carente de vida y por tanto de verdad, una vía muerta: un ídolo.

"Nada valora convenientemente quien no tiene en cuenta las condiciones de su dignidad",35; y, así las cosas, no podemos olvidar que somos en tanto que amados e invitados a amar; que Dios está con nosotros, íntimamente presente; que estamos abiertos, siempre, al Otro; que sólo cuando lo olvidamos, cuando el otro deja de ser el Camino, la Verdad y la Vida, y dejamos de estar disponibles, es posible creer que todo está ya dado, dicho, presente, desde el principio, que nada es irreductible a la quietud de la mismidad del Uno atemporal o inabarcable, que nada es novedad, que el tiempo es un error de perspectiva, un olvido de los hechos, una caída a remediar, un desajuste resoluble; que certidumbre es felicidad: la medicina sanadora, el refugio en el que guarecerse del devenir aterrador y la incontrolable presencia del otro.

La sabiduría puede entenderse como logro final, como cierre, reposo, evidencia e indisponibilidad, pero, entonces, ¿qué le responderemos a quién nos pregunte cuál es el amor de nuestra alma?, ¿qué le diremos a quién quiera saber qué nos mueve a buscar?, ¿qué diremos que nos hace filósofos?, ¿qué temple de ánimo diremos que late en nuestras más íntimas y profundas entrañas?; ¿el miedo ante la posibilidad de ser barridos por el sinsentido?, ¿tal vez la añoranza, la nostalgia de lo que fuimos, de lo que somos y podemos ser, es decir, el orgullo, la codicia, la melancolía...?

"La ley del siervo es el temor que le invade. La del asalariado es la codicia que le domina, le atrae y le distrae. Ninguna de estas leyes es pura y capaz de convertir a las almas. El amor, en cambio, convierte a las almas y las hace también libres" $"$.

No hay filosofía, en su sentido más profundo, sin conversión, decía Platón; sin conversión del corazón, entenderá Agustín; sin humilde entrega a lo otro que yo, a lo que me trasciende de modo absoluto. Porque filosofar es responder a la

33 San Agustín de Hipona, Confesiones X, 27, 38, 424.

34 San Agustín de Hipona, Confesiones III, 6, 11, 142.

35 San Buenaventura, De la vida perfecta, C. I, 5, en Experiencia y teología del misterio, (Madrid: B.A.C., 2000), 231.

36 San Bernardo de Claraval, Libro del amor a Dios, XII, 34, en Obras completas de San Bernardo II, (Madrid: B.A.C., 1983), 351. 
invitación a amar que nos constituye, entregándonos a la verdad, que es vida, que nos vivifica, y nos hace imposible contentarnos con lo que es y no puede ser de otro modo que como es, lo evidente, claro y distinto, acabado, cerrado, demostrado, fijado, definido, determinado, garantizado, acotado, sido, muerto: mío.

"El panteísta se halla eternamente tranquilizado hacia atrás" escribió Kierkegaard $^{37}$, pero el filósofo no puede encontrar esa tranquilidad, ni ansiarla, "la certidumbre es imposible para quien está en devenir, y es precisamente un fraude. Para utilizar el símil de una relación erótica -nos confía Kierkegaardimaginemos a una joven enamorada que anhela el día de su boda porque ésta le ha de proporcionar una firme certidumbre, imaginemos que busca la comodidad que como casada proporciona la seguridad juridica, e imaginemos que en lugar de suspirar como una novia bosteza como una casada. El amado se lamentaría con razón de su infidelidad, no porque amase a ningún otro, sino por haber perdido la idea del amor, y, por ende, por no amarlo propiamente. Tal es la infidelidad esencial en una relación amorosa"38.

"En este poema de amor -que es la existencia-no se puede tener en cuenta la materialidad de las palabras -celebró San Bernardo comentando el libro del amor, el Cantar de los Cantares- [...] Aqui habla siempre el amor; y el que desee enterarse de su lectura, que ame. De lo contrario, el que no ama se dispondrá en vano a escuchar o leer este poema de amor. Un corazón frívolo no puede en modo alguno percibir estas ardientes palabras. Así como ignorando el griego no se puede entender al que habla en ese idioma, o un no latino no comprende al que habla en latín, y así en los demás casos, de la misma manera el idioma del amor, incomprensible para el que no ama, sonará como una campana ruidosa o como unos platillos estridentes"39.

\section{REFERENCIAS BIBLIOGRÁFICAS}

Aristóteles. Metafísica. Madrid: Gredos, 1994.

—. Ética a Nicómaco. Madrid: Centro de Estudios Constitucionales, 1989.

Platón. República. Madrid: Gredos, 1992.

Plotino. Enéadas. Madrid: Gredos, 1982, 1985, 1998.

37 Søren Kierkegaard, Post Scriptum no científico y definitivo a «Migajas Filosóficas», (Salamanca: Sígueme, 2010), 227.

38 Søren Kierkegaard (2010), Post Scriptum, 83.

39 San Bernardo de Claraval (1987), Sermones sobre el Cantar de los cantares 79, 1, en Obras completas de San Bernardo, V, (Madrid,:B.A.C., 1987), 983. 
Pseudo Dionisio Areopagita. Obras completas. Madrid: B.A.C., 1990.

San Agustín. Confesiones. Madrid: B.A.C., 1998.

—. La Trinidad. Madrid: B.A.C., 2006.

San Bernardo de Claraval. Sermones sobre el Cantar de los cantares. En Obras completas de San Bernardo. Madrid: B.A.C., 1987.

San Buenaventura. Colaciones sobre el hexaémeron. En Obras de San Buenaventura, III. Madrid: B.A.C., 1947.

- Cuestiones disputadas de la ciencia de Cristo. Murcia: Editorial Espigas, 1999.

-. Itinerario de la mente hacia Dios, Experiencia y teología del misterio. Madrid: B.A.C., 2000.

San Gregorio de Nisa. Vida de Moisés. Salamanca: Sígueme, 1993.

Søren Kierkegaard. Migajas filosóficas, o un poco de filosofía. Madrid: Editorial Trotta, 1997.

—. Post Scriptum. Salamanca: Sígueme, 2010.

Ignacio Verdú Berganza Departamento de Filosofía, Humanidades y Comunicación Universidad Pontificia Comillas Calle de Alberto Aguilera, 23, 28015 Madrid, htps://orcid.org/0000-0002-1151-0271 